\title{
The effect of consecutive days of exercise on markers of oxidative stress
}

\author{
Cecilia M. Shing, Jonathan M. Peake, Shannon M. Ahern, Natalie A. Strobel, \\ Gary Wilson, David G. Jenkins, and Jeff S. Coombes
}

\begin{abstract}
We examined the influence of 3 consecutive days of high-intensity cycling on blood and urinary markers of oxidative stress. Eight highly-trained male cyclists $\left(V \mathrm{O}_{2} \max 76 \pm 4 \mathrm{~mL} \cdot \mathrm{kg}^{-1} \cdot \mathrm{min}^{-1}\right.$; mean $\left.\pm \mathrm{SD}\right)$ completed an interval session (9 exercise bouts lasting $30 \mathrm{~s}$ each, at $150 \%$ peak power output) on day 1, followed by 2 laboratory-simulated $30 \mathrm{~km}$ time trials on days 2 and 3. The cyclists also completed a submaximal exercise trial matched to the interval session for oxygen consumption. Blood was collected pre- and post-exercise for the determination of malondialdehyde (MDA), total antioxidant status (TAS), vitamin E, and the antioxidant enzyme activity of superoxide dismutase and glutathione peroxidase, while urine was collected for the determination of allantoin. There were significant increases in plasma MDA concentrations $(p<0.01)$, plasma TAS $(p<0.01)$, and urinary allantoin excretion $(p<0.01)$ following the high-intensity interval session on day 1, whereas plasma vitamin E concentration significantly decreased $(p=0.028)$. Post-exercise changes in plasma MDA $(p=0.036)$, TAS concentrations $(p=0.039)$, and urinary allantoin excretion $(p=0.031)$ were all significantly attenuated over the 3 consecutive days of exercise, whereas resting plasma TAS concentration was elevated. There were no significant changes in plasma MDA, TAS, or allantoin excretion following submaximal exercise and there were no significant changes in antioxidant enzyme activity over consecutive days of exercise or following submaximal exercise. Consecutive days of high-intensity exercise enhanced resting plasma TAS concentration and reduced the post-exercise increase in plasma MDA concentrations.
\end{abstract}

Key words: cycling, malondialdehyde, total antioxidant status.

Résumé : Nous analysons l'effet de 3 séances, en autant de jours, d'exercice de forte intensité à vélo sur les marqueurs sanguins et urinaires du stress par oxydation. Huit cyclistes masculins très bien entraînés $\left(V \mathrm{O}_{2} \max 76 \pm 4 \mathrm{~mL} \cdot \mathrm{kg}^{-1} \cdot \mathrm{min}^{-1}\right.$; moyenne \pm ÉT) participent le jour 1 à une séance d'entraînement par intervalles et réalisent 9 efforts d'une durée de $30 \mathrm{~s}$ à une intensité équivalent à $150 \%$ de leur puissance de pointe produite; aux jours 2 et 3, ils participent en laboratoire à deux courses simulées contre la montre sur une distance de $30 \mathrm{~km}$. Les cyclistes réalisent aussi un exercice sous-maximal et consomment la même quantité d'oxygène que celle consommée au cours de la séance d'entraînement par intervalles. Avant et après la séance d'effort, on prélève des échantillons sanguins afin d'analyser le contenu en propanedial (MDA), le bilan antioxydant global (TAS), la concentration de vitamine E et l'activité de la superoxyde dismutase et de la glutathion peroxydase; de plus, on recueille un échantillon d'urine pour analyser la concentration d'allantoïne. Le jour 1, on observe après la séance d'entraînement par intervalles une augmentation significative de la concentration plasmatique de MDA $(p<0,01)$, du TAS $(p<0,01)$ et de la concentration urinaire d'allantoïne $(p<0,01)$, mais on observe aussi une diminution de la concentration plasmatique de vitamine $\mathrm{E}(p=0,028)$. Aux jours 1,2 et 3 , on observe après la séance d'exercice une diminution significative de la concentration plasmatique de MDA $(p=0,036)$ et du TAS $(p=0,039)$ et de la concentration urinaire d'allantoïne $(p=0,031)$; le TAS plasmatique demeure cependant élevé au repos. On n'observe pas de variations significatives des concentrations plasmatiques de MDA, du TAS et de la concentration urinaire d'allantoïne à la suite de l'effort sous-maximal et on n'observe pas de variations significatives de l'activité des enzymes antioxydantes tout au long de ces trois journées et à la suite de l'effort sous-maximal. Des séances quotidiennes consécutives constituées d'un effort de forte intensité augmentent le TAS plasmatique au repos et diminuent la concentration plasmatique de MDA après l'effort.

Mots-clés : effort à vélo, propanedial, bilan antioxydant global.

[Traduit par la Rédaction]

\section{Introduction}

Exercise is associated with an increased production of free radicals and reactive oxygen species (ROS), and excess production of ROS has been linked to damage (oxidation) of lipids, proteins, and DNA through a process termed oxida-

Received 6 July 2006. Accepted 21 February 2007. Published on the NRC Research Press Web site at apnm.nrc.ca on 15 June 2007.

C.M. Shing, ${ }^{1}$ J.M. Peake, S.M. Ahern, N.A. Strobel, G. Wilson, D.G. Jenkins, and J.S. Coombes. Exercise and Oxidative Stress Research Group, School of Human Movement Studies, Connell Building, University of Queensland, St. Lucia, Queensland 4072, Australia.

${ }^{1}$ Corresponding author (e-mail: cecilia.shing@utas.edu.au). 
tive stress (Jenkins and Goldfarb 1993). Lipid peroxidation of cell membranes changes membrane integrity, leads to increased swelling, and reduces the ability of the cell to maintain ion gradients (Merry et al. 1991). This oxidative damage to cell membranes has been associated with tissue inflammation, muscle fatigue, and impaired recovery following high-intensity exercise (Pyne 1994; Abuja 2001).

Although there is a considerable volume of literature reporting the incidence of oxidative stress in trained and untrained individuals in response to acute bouts of exercise (see Konig et al. (2001) for a review), limited research has investigated the extent of oxidative stress following consecutive days of training in moderately to highly trained endurance athletes (Mena et al. 1991; Viguie et al. 1993; Subudhi et al. 2001) that often train at high intensities for prolonged periods of time. Many endurance athletes also race over consecutive days, which may increase their risk of incurring oxidative damage. Although adaptations to exercise-induced oxidative stress have been reported following extended training periods in rats (Criswell et al. 1993; Senturk et al. 2001; Petibois and Deleris 2005) and humans (Ji 2002), it remains unclear as to whether oxidative defense systems have the capacity to accommodate the oxidative stress resulting from consecutive days of intense exercise (Viguie et al. 1993; Okamura et al. 1997). Although the effects of oxidative stress on exercise performance are unclear (Child et al. 2000), inhibition of lipid peroxidation is associated with a reduction in muscular fatigue and attenuation of inflammation (Messina et al. 2006), whereas a decrease in glutathione oxidation delays muscle fatigue (Matuszczak et al. 2005). Oxidative stress occurrence and alterations in antioxidant defenses following exercise may influence subsequent exercise performance and oxidative stress responses over consecutive days of training.

The aim of the present investigation was to examine potential changes in urine and hematological markers of oxidative stress and markers of endogenous antioxidant status in highly trained cyclists over 3 consecutive days of aerobic and anaerobic exercise to reflect the high-intensity demands of cyclists' training. We hypothesized that consecutive days of high-intensity exercise without dietary intervention would result in a cumulative increase in oxidative stress and a decrease in antioxidant defenses.

\section{Materials and methods}

\section{Overview}

Following a familiarization visit and determination of $V \mathrm{O}_{2}$ max , subjects attended the Human Performance Laboratory at the University of Queensland for 3 consecutive days and performed (i) a high-intensity interval session, (ii) a 30 $\mathrm{km}$ time trial, and (iii) a second $30 \mathrm{~km}$ time trial. Between 4 and 6 days later, subjects performed a submaximal trial in which total oxygen consumed was equal to that consumed during the interval session.

\section{Subjects}

Eight highly-trained male road cyclists with a $V \mathrm{O}_{2}$ max of $76 \pm 4 \mathrm{~mL} \cdot \mathrm{kg}^{-1} \cdot \mathrm{min}^{-1}$ (mean $\pm \mathrm{SD}$ ) volunteered to participate in the study (Table 1). Cyclists had a minimum of 2 years competitive racing experience. All cyclists refrained from taking any dietary or vitamin supplements 1 month prior to and for the duration of the study. They completed a medical history questionnaire and gave their written consent to participate; the study was approved by an ethics committee at The University of Queensland. For all visits, cyclists reported to the laboratory in a fasted and rested state. They had abstained from strenuous exercise for $36 \mathrm{~h}$ prior to the first day of consecutive high-intensity training and before the final submaximal trial. Four highly active males with $V \mathrm{O}_{2 \text { max }}$ of $60 \pm 6 \mathrm{~mL} \cdot \mathrm{kg}^{-1} \cdot \mathrm{min}^{-1}$ volunteered to participate as control subjects (Table 1). Highly trained male cyclists were unable to be obtained as control subjects, as they would have had to refrain from training for 4 consecutive days, which conflicted with their training schedules. The control subjects agreed to refrain from taking any dietary or vitamin supplements 1 month prior to and for the duration of the study. In addition to completing a medical history questionnaire and giving their written consent to participate, they were required to abstain from exercise for a period of 4 days. Rested and fasted blood samples were taken at the same time of day on days 2,3 , and 4 . This coincided with blood sampling of the exercising subjects over the 3 consecutive days of high-intensity exercise.

\section{Familiarization}

A familiarization visit required cyclists to complete a 30 min submaximal ride with the equipment (mouthpiece, headgear, and cycle ergometer) used in the $V_{2}$ max test. During this visit cyclists also completed 3 high-intensity interval bouts $(30 \mathrm{~s}$ at $620 \mathrm{~W})$ to familiarize them with the intensity of the interval session.

\section{$\mathrm{VO}_{2 \max }$ testing}

Cyclists exercised to fatigue on an electronically braked cycle ergometer (Lode Excalibur Sport, Quinton) modified with clip-in pedals and low-profile racing handlebars; the saddle and handle bar positions of the cycle ergometer were adjusted to resemble each cyclists' own bike, and subjects warmed up at a self-selected pace for $5 \mathrm{~min}$. The incremental test commenced at an initial workload of $100 \mathrm{~W}$; workload thereafter increased by $15 \mathrm{~W}$ every $30 \mathrm{~s}$ until volitional fatigue. Oxygen consumption and carbon dioxide production were measured continuously, and data were recorded by a Lab View Computer Program (South Australian Sports Institute). Expired air was analyzed for fractions of expired oxygen $\left(\mathrm{F}_{\mathrm{E}} \mathrm{O}_{2}\right)$ and carbon dioxide $\left(\mathrm{F}_{\mathrm{E}} \mathrm{CO}_{2}\right)$ every $15 \mathrm{~s}$ during exercise (Ametek gas analyzers; SOV S-3A11 and COV CD3A, Pittsburgh, PA), and minute ventilation $\left(V_{\mathrm{E}}\right)$ was recorded every $15 \mathrm{~s}$ using a turbine ventilometer (Morgan, Model 096, Kent, England). The gas analyzers were calibrated immediately before and validated after each test using a certified beta gas mixture (Commonwealth Industrial Gas Ltd., Brisbane, Australia); the ventilometer was calibrated before and validated after each test using a $1 \mathrm{~L}$ syringe in accordance with the manufacturer's instructions. $V \mathrm{O}_{2}$ max was assumed when two of the following conditions occurred: $(i)$ the oxygen consumption ceased to increase linearly with a rising workload and approached a plateau or dropped slightly, the last two values agreeing within \pm $2 \mathrm{~mL} \cdot \mathrm{kg}^{-1} \cdot \mathrm{min}^{-1}$; (ii) $90 \%$ of age-predicted maximum heart rate $\left(\mathrm{HR}_{\max }\right)$ was attained; and (iii) respiratory exchange 
Table 1. Subject characteristics.

\begin{tabular}{llllll}
\hline & Age $(\mathrm{y})$ & Mass $(\mathrm{kg})$ & Height $(\mathrm{cm})$ & $V \mathrm{O}_{2 \mathrm{max}}\left(\mathrm{mL} \cdot \mathrm{kg}^{-1} \cdot \mathrm{min}^{-1}\right)$ & $\mathrm{PPO}(\mathrm{W})$ \\
\hline Highly trained $(n=8)$ & $25(4)$ & $67.7(6.2)$ & $176.4(6.7)$ & $75.6(4.1)$ & $433(37)$ \\
Control $(n=4)$ & $25(1)$ & $68.0(2.5)$ & $175(6.9)$ & $60.7(6.3)$ & $401(38)$ \\
\hline
\end{tabular}

Note: PPO, peak power output. Data are presented as mean $\pm \mathrm{SD}$.

ratio (RER) was greater than $1.10 . V \mathrm{O}_{2 \max }$ was recorded as the highest $V \mathrm{O}_{2}$ value averaged over two consecutive readings, and the peak power output was recorded as the highest $30 \mathrm{~s}$ power output completed during the incremental test.

\section{High-intensity interval session}

Between 4 and 6 days following the $\mathrm{VO}_{2}$ max test cyclists completed the high-intensity interval session. They performed nine $30 \mathrm{~s}$ bouts at $150 \%$ of peak power output; 4.5 min of low-intensity exercise (cycling at $50 \mathrm{~W}$ ) separated each bout (exercise time was comparable with the time to complete the $30 \mathrm{~km}$ time trial). The cyclists exercised on the electronically braked cycle ergometer, and oxygen uptake was monitored for the entire session (i.e., during the exercise and recovery periods). One minute prior to the commencement of each interval, subjects could remove their mouthpiece to consume water. Oxygen consumption from the previous $30 \mathrm{~s}$ reading and the $30 \mathrm{~s}$ reading following water intake were averaged to estimate oxygen consumption for the $30 \mathrm{~s}$ period during which the mouthpiece was removed. The amount of water consumed by cyclists in each of the 4 testing sessions was between 400 and $500 \mathrm{~mL}$. Total oxygen consumption was determined during the highintensity interval session. Oxidative stress variables were compared between the high-intensity interval session and the point during the submaximal ride at which total oxygen consumption (and energy expenditure) was the same.

\section{Time trials}

Two laboratory simulated $30 \mathrm{~km}$ time trials were completed by the cyclists on days 2 and 3; exercise was performed by each cyclist on his own bicycle that was mounted to a stationary windtrainer (Cateye, Cyclosimulator CS-1000, Japan). The rear tire was inflated to $120 \mathrm{psi}$ (1 psi = $6.89 \times 10^{-3} \mathrm{~Pa}$ ), and placed gently against the friction device before it was secured; the spring-loaded release brake was removed and a wind-regulated friction load was placed against the rear wheel. Each cyclists' same rear wheel was used for both $30 \mathrm{~km}$ time trials. Performance time was blinded to the subject during the $30 \mathrm{~km}$ time trial, but was revealed to him on completion of the trial.

\section{Submaximal ride}

Between 4 and 6 days following the second $30 \mathrm{~km}$ time trials, cyclists completed a submaximal ride during which the exercise intensity and duration were calculated to ensure that total oxygen consumed was equal to the total oxygen consumed during the interval session. Each cyclists' own road bicycle was mounted to a stationary windtrainer, in the same manner as described for the $30 \mathrm{~km}$ time trials. Cyclists were able to observe their speed $\left(\mathrm{km} \cdot \mathrm{h}^{-1}\right)$ and oxygen consumption was monitored every $7 \mathrm{~min}$ (for $3 \mathrm{~min}$ intervals) throughout the ride to ensure that the cyclists were riding at the required oxygen consumption.

\section{Dietary analysis}

Both cyclists and control subjects recorded their food intake for a $24 \mathrm{~h}$ period prior to all experimental testing sessions. Diet was analyzed using Foodworks Professional (Xyris Software, Australia), which provided information on energy intake in addition to macro- and micro-nutrient intake.

\section{Urine collection}

Urine was collected pre- and post-exercise for the highintensity interval session, both $30 \mathrm{~km}$ time trials, and the submaximal session. Each cyclist was instructed to empty his bladder $1 \mathrm{~h}$ prior to arriving at the laboratory. He then immediately consumed $250 \mathrm{~mL}$ of water. Ten minutes prior to exercise, after arrival at the laboratory, each cyclist was again instructed to empty his bladder. Urine was again collected from 0 to $30 \mathrm{~min}$ post-exercise. All samples were collected by voluntary voiding in a container provided to the subject. Urine $(40 \mathrm{~mL})$ was acidified with $600 \mu \mathrm{L}$ of $1 \mathrm{~mol} /$ $\mathrm{L} \mathrm{H}_{2} \mathrm{SO}_{4}$ and stored at $-20{ }^{\circ} \mathrm{C}$ for later analysis.

\section{Urinary allantoin}

Allantoin was measured in urine because, once produced, it is cleared into the urine relatively quickly (Benzie et al. 1999; Hellsten et al. 1997; Mikami et al. 2000). The assay for determination of urinary allantoin concentration was developed using a combination of previously published methods by Shingfield and Offer (1999) and Grootveld and Halliwell (1987) with the following modifications. Urine samples were extracted with acetonitrile and added to hexane. They were placed in a freezer at $-80{ }^{\circ} \mathrm{C}$ for $10 \mathrm{~min}$ to enable the aqueous phase to freeze. The mixture was then removed from the freezer and the hexane phase poured off and discarded, while the remaining aqueous phase was left to thaw. The thawed mixture was then evaporated using a Thermo Savant speed vacuum (SPD 111v) set at a temperature of $35{ }^{\circ} \mathrm{C}$ for a period of $30 \mathrm{~min}$, after which it was reconstituted with formic acid prior to processing.

The concentrations of allantoin in extracted samples were determined by liquid chromatography - mass spectrometry (LC/MS) using a gradient high-performance liquid chromatography (HPLC) system (Shimadzu LC-10AT system, Japan) coupled to a triple quadruple mass spectrometer (Perkin Elmer Sciex API 3000) operating in single ion monitoring mode with positive ion electrospray. Each sample was analyzed for the presence of allantoin (extraction peak at 159.1 molecular weight). $\mathrm{A}_{18}$ column $(5 \mu \mathrm{m}, 50 \times$ $2.0 \mathrm{~mm}$ ) (Phenomenex) was used for reverse-phase HPLC at a flow rate of $0.2 \mathrm{~mL} \cdot \mathrm{min}^{-1}$. The mobile phase used in the initial 6 min isocratic stage of each run was solvent A ( $0.1 \%$ formic acid in water). This isocratic stage was fol- 
lowed by a 3 min washing - re-equilibrating cycle that involved taking solvent $\mathrm{A}$ to $80 \%$ solvent $\mathrm{B}(0.1 \%$ formic acid in $90 \%$ acetonitrile - water) for 2 min and then changing back to $100 \%$ solvent A for 1 min. A $10 \mu \mathrm{L}$ injection of each sample was analyzed. Recovery of spiked samples was $91.3 \%$ and the interassay coefficient of variation was $4.5 \%$. Allantoin is released rapidly from muscle to blood in response to the non-enzymatic oxidation of urate and is then cleared into the urine relatively quickly (Benzie et al. 1999; Hellsten et al. 1997; Mikami et al. 2000). Allantoin was expressed relative to the volume of urine produced and not corrected for creatinine, as the relationship between creatinine and allantoin excretion is weak at high allantoin concentrations.

\section{Blood collection}

Fasted blood samples $(10 \mathrm{~mL})$ were drawn from an antecubital vein into heparinized vacutainers; blood was taken $10 \mathrm{~min}$ before and $5 \mathrm{~min}$ after exercise. Hematocrit was determined in duplicate by microcentrifugation of blood in microtubes and hemoglobin was measured using standard techniques (Drabkin 1965). The change in plasma volume was calculated according to the method of Dill and Costill (1974).

Collected blood was centrifuged at $1500 \mathrm{~g}$ for $10 \mathrm{~min}$ at $4{ }^{\circ} \mathrm{C}$. The plasma was collected and stored at $-80{ }^{\circ} \mathrm{C}$ until later analysis. Two millilitres of red blood cells were washed with $20 \mathrm{~mL}$ of cold buffer $(50 \mathrm{mmol} / \mathrm{L}$ Tris- $\mathrm{HCl}$ $(\mathrm{pH}$ 7.6), $5 \mathrm{mmol} / \mathrm{L}$ ethylenediaminetetraacetic acid, $1 \mathrm{mmol} / \mathrm{L}$ dithiothreitol) and again centrifuged at $1500 \mathrm{~g}$ for $10 \mathrm{~min}$ at $4{ }^{\circ} \mathrm{C}$. The supernatant was then removed and discarded and the red blood cells were lysed in 4 times their volume of ice-cold $\mathrm{ddH}_{2} \mathrm{O}(1 \mathrm{~mL}$ red blood cells to $4 \mathrm{~mL}$ $\mathrm{ddH}_{2} \mathrm{O}$ ). This mixture was then centrifuged (1500g for $10 \mathrm{~min}$ at $4{ }^{\circ} \mathrm{C}$ ) and the remaining supernatant collected and frozen at $-80{ }^{\circ} \mathrm{C}$ until later analysis.

\section{Vitamin E}

Plasma concentrations of vitamin E ( $\alpha$-tocopherol), total carotenoids, and total free cholesterol were determined by reverse-phase HPLC using the liquid-liquid extraction method of (Taibi and Nicotra 2002). Briefly, proteins were precipitated with Ethanol:BHT $\left(200 \mathrm{~g} \cdot \mathrm{L}^{-1}\right)$, followed by a hexane lipid extraction. After separation of the precipitated protein, $700 \mu \mathrm{L}$ hexane was speed dried (Savant RVT400 and Savant SpeedVac SPDIIIV, Holbrook, NY, USA) and reconstituted with $100 \mu \mathrm{L}$ methanol. Total carotenoids and vitamin $\mathrm{E}$ were mearsured using fluorometric detection and electrochemical detection for total cholesterol via injection of $40 \mu \mathrm{L}$ into a LiChrospher C18 column $(250 \times 4 \mathrm{~mm}$, $5 \mu \mathrm{m}$; Merck, Darmstadt, Germany), with a flow rate of $0.8 \mathrm{~mL} \cdot \mathrm{min}^{-1}$ and $10.3 \mathrm{MPa}$ backpressure. Separate stock solutions of $d l$ - $\alpha$-tocopherol (Fluka, Buchs, Switzerland) and lycopene and $\alpha$ - and $\beta$-carotene for total carotenoids and cholesterol (Sigma, St. Louis, Mo.) were used as external standards.

\section{Malondialdehyde}

HPLC was used to determine plasma malondialdehyde (MDA) using the method of Sim et al. (2003). The principle of this method is that malondialdehyde contained in plasma is derivatized with 2,4-dinitrophenylhydrazine, which forms stable hydrazones that can be easily separated by HPLC using diode array detection (Shimadzu, Kyoto, Japan).

\section{Total antioxidant status}

Total antioxidant status was determined by the method of Miller et al. (1993), which is based on the inhibition by antioxidants of the absorbance of the radical cation 2,2'-azinobis (3-ethylbenzthiazoline-6-sulfonate) $\left(\mathrm{ABTS}^{+}\right)$. This radical cation is formed by the interaction of ABTS with the ferrylmyoglobin radical species, generated by the activation of metmyoglobin with hydrogen peroxide. Antioxidant compounds suppress the absorbance of the $\mathrm{ABTS}^{+}$radical cation to an extent and on a time scale dependent on the antioxidant capacity of the plasma. The assay was carried out on a Cobas Mira automated spectrophotometer (Roche Diagnostics, Basel, Switzerland). Plasma total antioxidant status was corrected for changes in plasma volume.

\section{Antioxidant enzymes}

Erythrocyte glutathione peroxidase (GPX) and superoxide dismutase (SOD) activities were determined according to the methods of Wheeler et al. (1990) and Madesh and Balasubramanian (1998), respectively. The assays were modified to be performed on the Cobas Mira spectrophotometer. All enzyme activities were normalized to haemoglobin concentration.

\section{Statistical analysis}

All statistical analyses were performed using SPSS version 10.0 for Windows (SPSS, Chicago, Ill.). Data was first tested for normality using the Kolmogorov-Smirnov and Shapiro-Wilk tests. To examine the effects of the 3 consecutive days of training a time (pre- and post-exercise) $\times$ trial (day 1, day 2, and day 3 ) repeated-measures analysis of variance (ANOVA) and an ANOVA for the absolute change in values over the 3 days was used with $p<0.05$ as significant. When a significant main effect was found, differences between trials were determined using the multiple-comparison false-discovery rate procedure (Curran-Everett 2000). The false-discovery rate was set at $p<0.05$ (Table 2). Comparisons were significant when the $p$ value determined from a $t$ test was less than the calculated critical value. In addition, percentage changes and effect sizes (ES) for the difference between pre- and post-exercise means were calculated. ES was interpreted as follows: $0.2=$ small, $0.5=$ moderate, and $0.8=$ large; these terms are used in the results section (Thomas et al. 1991).

\section{Results}

The primary aim of this study was to investigate the changes in markers of oxidative stress and antioxidant defenses after consecutive days of exercise in highly trained cyclists. There were no significant differences between the control group and the exercising group for $V_{2}$ max, peak power output, height, weight, or age $(p>0.05)$. There were no significant differences for any of the control group measures over the experimental period $(p>0.05)$ (Fig. 1). Dietary macro- and micro-nutrient intakes were similar for each exercise trial $(p>0.05)$, and there were no significant differ- 
Table 2. Calculations for false-discovery rate procedure.

\begin{tabular}{|c|c|c|c|c|c|c|}
\hline \multirow[b]{2}{*}{ Comparison } & \multicolumn{2}{|l|}{ TAS } & \multicolumn{2}{|c|}{ Allantoin } & \multicolumn{2}{|l|}{ MDA } \\
\hline & $p$ value & Critical value & $p$ value & Critical value & $p$ value & Critical value \\
\hline pre-IS vs. post-IS & 0.000 & $0.033 *$ & 0.001 & $0.033 *$ & 0.002 & $0.017 *$ \\
\hline pre-TT 301 vs. post- $\mathrm{TT}_{30} 1$ & 0.003 & $0.008 *$ & 0.521 & 0.042 & 0.016 & $0.033^{*}$ \\
\hline pre-TT 302 vs. post-TT 302 & 0.011 & $0.025 *$ & 0.723 & 0.050 & 0.214 & 0.008 \\
\hline pre-SM vs. post-SM & 0.218 & 0.050 & 0.054 & 0.050 & 0.234 & 0.050 \\
\hline pre-IS vs. pre-TT ${ }_{30} 1$ & 0.011 & $0.017^{*}$ & 0.162 & 0.025 & 0.003 & $0.042 *$ \\
\hline pre-IS vs. pre- $\mathrm{TT}_{30} 2$ & 0.026 & $0.033 *$ & 0.392 & 0.033 & 0.035 & 0.033 \\
\hline post-IS vs. post-SM & 0.005 & $0.017 *$ & 0.000 & $0.017 *$ & 0.031 & $0.033^{*}$ \\
\hline post-IS vs. post-TT ${ }_{30} 1$ & 0.611 & 0.050 & 0.040 & 0.017 & 0.078 & 0.025 \\
\hline post-IS vs. post-TT 302 & 0.611 & 0.042 & 0.015 & 0.008 & 0.126 & 0.017 \\
\hline
\end{tabular}

Note: False-discovery rate set at 0.05 . TAS, total antioxidant status; MDA, malondialdehyde; SM, submaximal; IS, interval session; TT $_{30}, 30 \mathrm{~km}$ time trial. $p$ value $=$ achieved significance level from $t$ test.

*Denotes significance $(p$ value $<$ critical value $)$

ences for pre-exercise measures for the interval session and submaximal trial (average exercise intensity of $58 \%$ $\left.V \mathrm{O}_{2 \max }\right)$ for the experimental group $(p>0.05)$.

There was a significant time $\times$ trial interaction for plasma MDA concentration over the 3 days of high-intensity exercise $(p=0.046)$. The magnitude of the post-exercise increase in plasma MDA concentration across the 3 days was also significantly different ( $\mathrm{ES}=0.6, p=0.036$ ). Postexercise plasma MDA concentration was significantly increased for the high-intensity interval session $(18 \%$, ES = 1.1) (Table 2). There was also a significant increase in plasma MDA concentration after the $30 \mathrm{~km}$ time trial 1 on day $2(16 \%, \mathrm{ES}=0.8)$; however, the post-exercise increase for $30 \mathrm{~km}$ time trial 2 on day 3 was not significant $(4 \%$, ES = 0.3 ) (Fig. 2a). Pre-exercise MDA concentrations were significantly elevated on day 2 ( $E S=1.0$ ), but returned to baseline values on day 3 of the consecutive days of highintensity exercise. Post-exercise MDA concentrations were not significantly increased for the submaximal session (3.3\%, ES = 0.4) (Fig. 2a).

There was a significant main effect of time on urinary allantoin excretion over the 3 consecutive days of exercise $(p=$ 0.031 ) (Fig. 2b). There was a large significant post-exercise increase in urinary allantoin excretion for the interval session on day $1(171 \%, \mathrm{ES}=1.7)$. However, there were no significant increases in urinary allantoin excretion for $30 \mathrm{~km}$ time trial 1 on day $2(38 \%, \mathrm{ES}=0.2)$ or $30 \mathrm{~km}$ time trial 2 on day $3(23 \%$, ES $=0.1)$. The magnitude of the change in urinary allantoin excretion was significantly reduced across the 3 consecutive days of high-intensity training $(p<0.01)$. There was a large post-exercise increase in urinary allantoin concentration following the submaximal session; however, this increase was not significant $(61 \%, \mathrm{ES}=1.1)$.

Plasma TAS concentrations were significantly elevated post-exercise following the interval session on day 1 $(13.4 \%, \mathrm{ES}=1.8)$ and both $30 \mathrm{~km}$ time trials on days 2 and $3(8.3 \%, \mathrm{ES}=1.1$ and $5.5 \%, \mathrm{ES}=0.7$; respectively $)(p<$ 0.001 ). There was also a significant decrease in the magnitude of post-exercise change in plasma TAS concentrations after exercise over the 3 consecutive days of high-intensity training $(p=0.039)$. Compared with pre-exercise values on day 1, pre-exercise plasma TAS was significantly elevated on days $2(\mathrm{ES}=0.6)$ and $3(\mathrm{ES}=0.8)$ of the consecutive days of high-intensity exercise (Fig. 3). There was no significant increase in plasma TAS concentration following the submaximal session $(1.3 \%$, ES $=0.2)$.

Plasma vitamin E concentration was significantly decreased post-exercise on day 1 of consecutive days of highintensity exercise $(-10.1 \%$, ES $=0.7)$; however, there were no significant changes detected between trials over the 3 consecutive days of exercise or following the submaximal trial $(1.8 \%$, ES = 0.1) (Fig. 4). Erythrocyte GPX and SOD activities remained unchanged following each exercise trial (Fig. 5).

\section{Discussion}

The aim of the present study was to determine the influence of consecutive days of high-intensity exercise on markers of oxidative stress and antioxidant status in highlytrained cyclists. Post-exercise increases in biomarkers of oxidative stress were reduced over 3 consecutive days of intense exercise, whereas resting plasma TAS concentrations were elevated on days 2 and 3 . Although intense exercise may increase lipid peroxidation, urate oxidation, and plasma TAS, such alterations are not necessarily accompanied by changes in erythrocyte antioxidant activity.

Lipid peroxidation, as indicated by plasma MDA concentration, increased significantly after the interval session and the second day of high-intensity training (i.e., first $30 \mathrm{~km}$ time trial). Although both the interval session and the 30 $\mathrm{km}$ time trial on day 2 elevated post-exercise plasma MDA concentration, there was no increase for the $30 \mathrm{~km}$ time trial performed on day 3. Lovlin et al. (1987) investigated the relationship between exercise intensity and lipid peroxidation in moderately-trained males $\left(V \mathrm{O}_{2} \max =47 \mathrm{~mL} \cdot \mathrm{kg}^{-1} \cdot \mathrm{min}^{-1}\right)$ and found that at exercise intensities of $40 \%$ and $70 \%$ $V \mathrm{O}_{2}$ max there was no evidence of oxidative stress assessed from MDA. Exercise intensity on days 2 and 3 of the consecutive days was comparable to $79 \% V_{2} \mathrm{O}_{2}$ max , thereforeit appears that the decrease in MDA concentration on day 3 was not related to a decrease in exercise intensity.

In the same pattern as plasma MDA concentrations, urinary allantoin excretion was reduced over the 3 consecutive days of high-intensity exercise. Allantoin is produced from the non-enzymatic oxidation of urate and elevated resting concentrations of urinary allantoin have been associated 
Fig. 1. Control subjects' variables over 3 consecutive non-exercising days. (A) Malondialdehyde (MDA). (B) Total antioxidant status (TAS). (C) Vitamin E. (D) Glutathione peroxidase (GPX). (E) Superoxide dismutase (SOD). Data are mean \pm SEM.
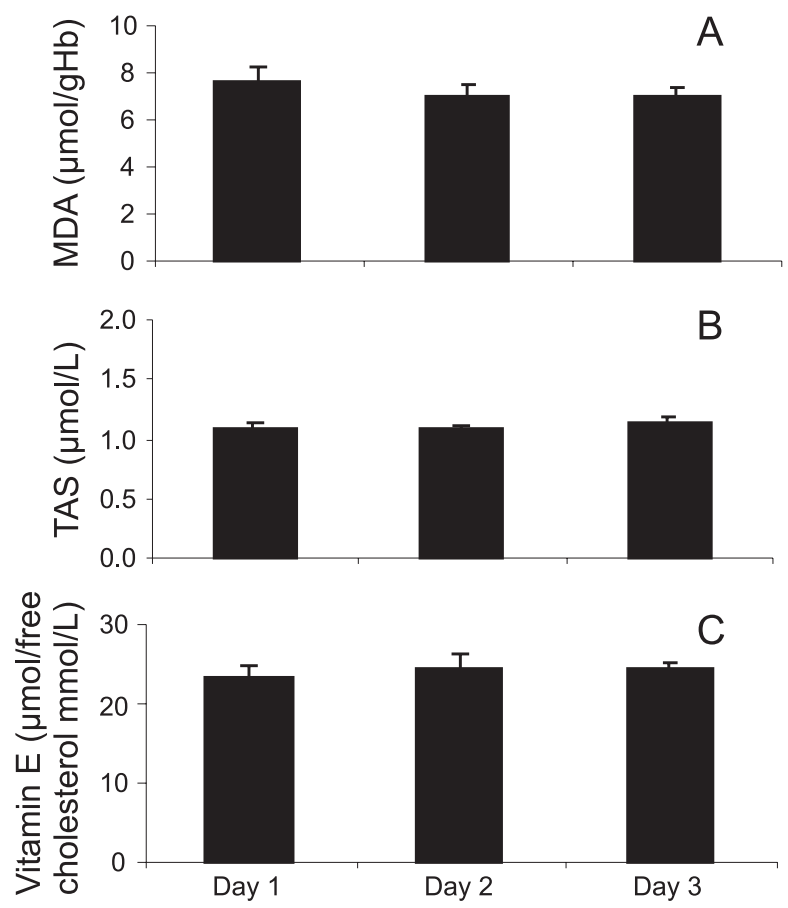

with oxidative stress conditions such as diabetes and rheumatoid arthritis (Benzie et al. 1999). Allantoin was significantly increased following the interval session on day 1 ; however, there was no increase in response to the $30 \mathrm{~km}$ time trial on days 2 and 3. It remains unknown whether allantoin excretion was unchanged following both $30 \mathrm{~km}$ time trials in response to an upregulation of TAS from exercise on day 1 , either owing to a decrease in the availability of urate as a substrate or as the result of unchanged levels of urate oxidation. Although allantoin excretion was not significantly increased following the submaximal trial, there was a large effect of exercise $(\mathrm{ES}=1.1)$ when compared with days 2 and 3 of the consecutive days of exercise. Allantoin has been produced following exercise at $100 \%$ and $90 \%$ $V \mathrm{O}_{2 \max }$, but not at $40 \% V_{2} \mathrm{O}_{2}$ (Mikami et al. 2000). In the present study, there was a large $(61 \%$, ES $=1.1)$ postexercise increase in allantoin excretion following submaximal exercise (average intensity of $58 \% \mathrm{VO}_{2} \max$ ); however, the post-exercise increase following the $30 \mathrm{~km}$ time trial on days 2 and 3 (average intensity of $79 \% V_{2}$ max ) was small (38\%, ES $=0.2$ and $23 \%, \mathrm{ES}=0.1$, respectively). Post-exercise allantoin excretion following exercise on days 2 and 3 , which was at a greater intensity than during the submaximal trial, may have been reduced as a result of adaptations to exercise on day 1 . The reduction in urinary allantoin concentrations observed with consecutive days of training may indicate a decrease in ROS production, or a greater contribution of antioxidants other than urate to scavenge ROS.

The progressive decline in markers of oxidative stress over 3 consecutive days of exercise may reflect a reduction in the production of ROS, an up-regulation and (or) adaptation of antioxidant defense mechanisms, or a decrease in substrate availability. Post-exercise plasma TAS concentrations were elevated following exercise on day 1 and resting
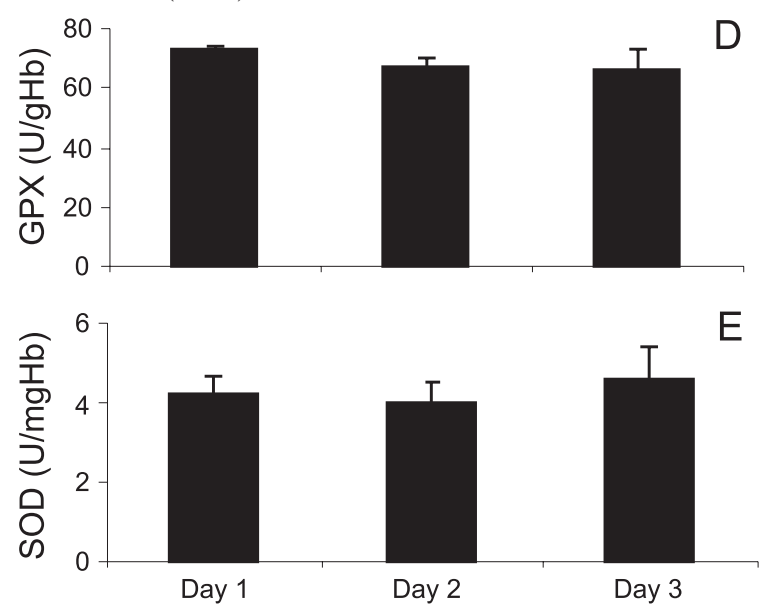

plasma concentrations were elevated on days 2 and 3. This upregulation of plasma antioxidants may represent a positive adaptation to consecutive days of high-intensity training. A major contributor to the total antioxidant activity of plasma is the antioxidant activity of urate (Subudhi et al. 2001). The amount of urate present in vivo prior to exercise has been shown to influence the extent of ROS production and reduce lipid peroxidation following cycling to fatigue (approx. 1018 min) (Green and Fraser 1988; Mikami et al. 2000). Although we did not measure plasma urate, previous reports indicate the plasma urate concentration is elevated $40 \%$ for $24 \mathrm{~h}$ following intermittent sprint cycle training at $120 \%$ $\mathrm{VO}_{2} \max$ (Green and Fraser 1988), which was an intensity lower than the interval session on day 1 in the present study. The increase in TAS concentration in the present study on days 2 and 3 may have contributed to a reduction in lipid peroxidation, as indicated by the reduced magnitude of post-exercise MDA concentration over the 3 consecutive days of high-intensity exercise. In contrast to the present findings, levels of lipid peroxidation following a half marathon have remained unchanged despite higher resting levels of plasma total antioxidant capacity (Child et al. 2000). The amount of protection against lipid peroxidation offered by elevated pre-exercise urate levels may be influenced by exercise duration.

Although plasma TAS concentrations were not depleted, vitamin $\mathrm{E}$ concentrations following the interval session were significantly reduced when compared with the submaximal exercise trial $(-10.1 \%$ vs. $1.8 \%$, respectively). Previous research has shown a decrease in plasma vitamin E concentration following a $30 \mathrm{~s}$ cycle sprint (Hutler et al. 2001) and a decrease in response to maximal treadmill exercise (Viguie et al. 1993; Vasankari et al. 1997). Following submaximal exercise, studies have reported either an increase or no 
Fig. 2. Plasma malondialdehyde concentration (A) and urinary allantoin excretion (B) pre- and post-exercise. Day 1, interval session; day 2, $30 \mathrm{~km}$ time trial 1; day 3, $30 \mathrm{~km}$ time trial 2; SM, submaximal. Data are mean \pm SEM. Asterisk $(*)$ denotes significantly different versus pre-exercise, $p<0.01$. Dagger $(\dagger)$ indicates that the change from pre- to post-exercise was significantly different between interval and SM sessions. Double dagger ( $\$$ ) indicates a significant difference between pre-exercise values.

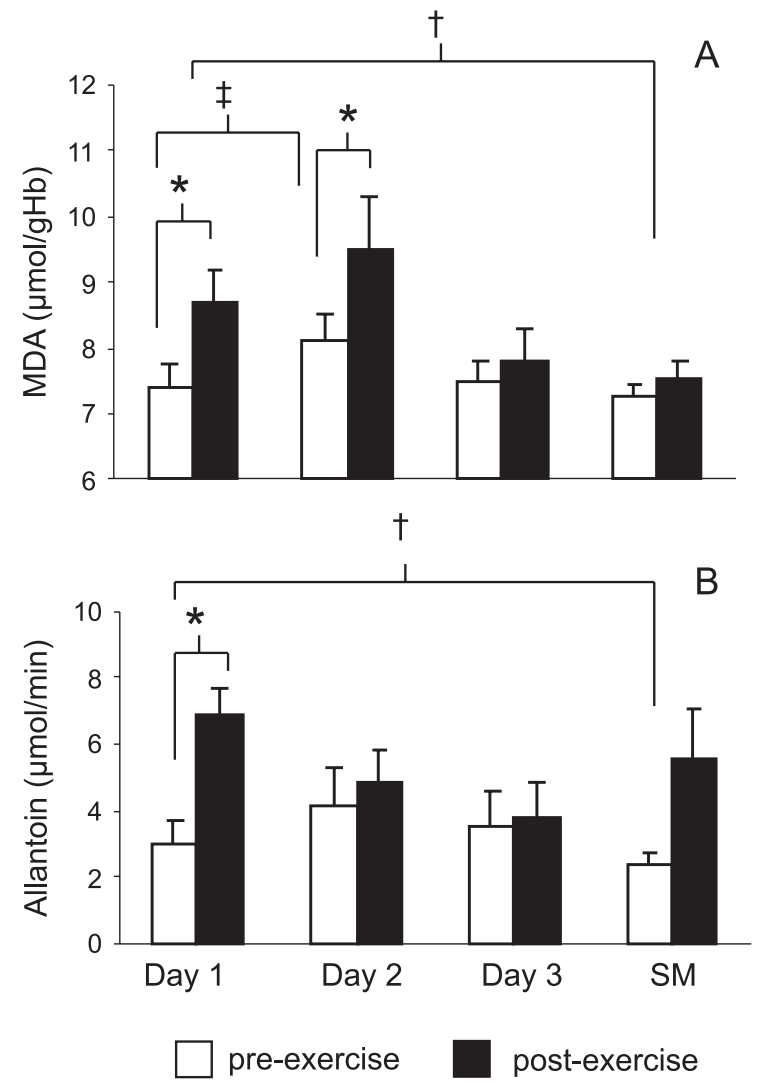

Fig. 3. Plasma total antioxidant status pre- and post-exercise. Day 1, interval session; day 2, $30 \mathrm{~km}$ time trial 1; day 3, $30 \mathrm{~km}$ time trial 2; SM, submaximal. Data are mean \pm SEM. Asterisk (*) denotes significantly different versus pre-exercise. Dagger $(\dagger)$ indicates that the change from pre- to post-exercise was significantly different between interval and SM sessions. Double dagger (†) indicates significant difference between pre-exercise values.

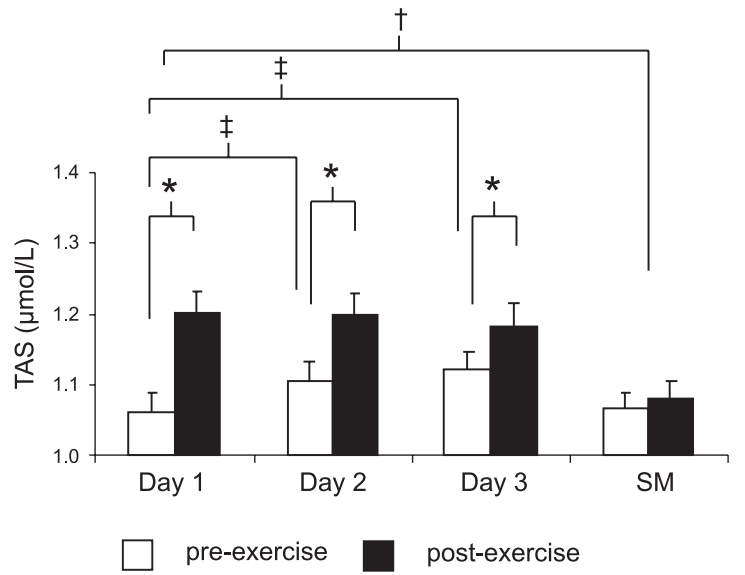

Fig. 4. Plasma vitamin E pre- and post-exercise. Day 1, interval session: day 2, $30 \mathrm{~km}$ time trial 1; day 3, $30 \mathrm{~km}$ time trial 2; SM, submaximal. Data are mean \pm SEM. Asterisk $(*)$ denotes significantly different versus pre-exercise.

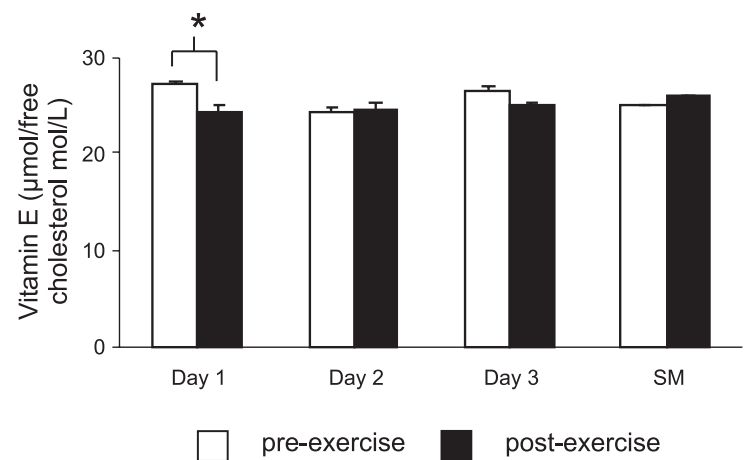

Fig. 5. Antioxidant enzyme activities pre- and post-exercise for each trial. (A) Glutathione peroxidase (GPX). (B) Superoxide dismutase (SOD). Data are mean \pm SEM.

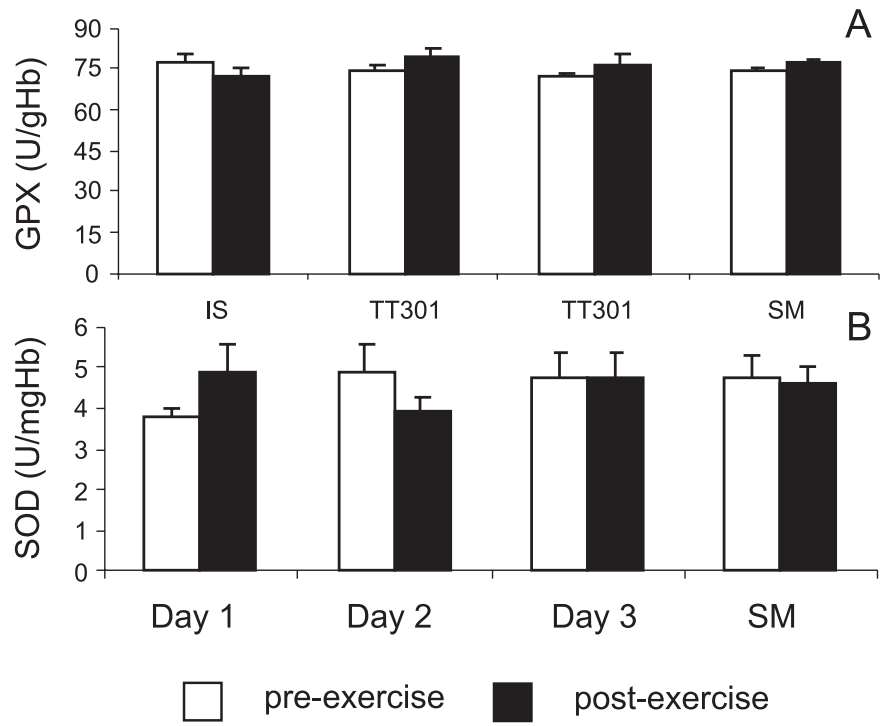

change in plasma vitamin $\mathrm{E}$ concentration (Burton et al. 1983). Together, with the present findings, these data suggest that a high-intensity interval session may more readily deplete vitamin $\mathrm{E}$ when compared with a $30 \mathrm{~km}$ time trial, to protect against increased oxidative stress. Vitamin $\mathrm{E}$ is an important component of the lipid membrane and offers protection against lipid peroxidation (Duthie et al. 1990; Dufaux et al. 1997; Marzatico et al. 1997; Groussard et al. 2003). The decrease in plasma vitamin $E$ following the interval session may have contributed to the increased susceptibility of lipids to peroxidation following the same trial, as indicated by the increase in plasma MDA concentration. Plasma MDA concentrations were, however, significantly elevated following the $30 \mathrm{~km}$ time trial on day 2, whereas plasma vitamin E levels were unchanged. The protective role of endogenous vitamin $\mathrm{E}$ in preventing lipid peroxidation at varying exercise intensities requires further investigation.

Reports of alterations in erythrocyte antioxidant enzyme activity after exercise are equivocal (Duthie et al. 1990). In the present study, erythrocyte GPX and SOD activities did 
not change in response to 3 consecutive days of high-intensity exercise or submaximal exercise. These findings are consistent with those of Duthie et al. (Subudhi et al. 2001), who found no change in erythrocyte GPX, catalase, or SOD activities in 7 highly trained males immediately and $5 \mathrm{~d}$ following a half-marathon. GPX activity has also remained unchanged over a period of land and snow training in elite alpine skiers (Tauler et al. 1999). In contrast to the present findings, previous research showed increased GPX activity in trained athletes both immediately and during $60 \mathrm{~min}$ of recovery following a duathlon race (Tauler et al. 1999). SOD activity has also been reported to increase following a $2800 \mathrm{~km}, 20 \mathrm{~d}$ road race (Mena et al. 1991). It is possible that the duration of exercise in the present study may not have been sufficient to alter erythrocyte antioxidant enzyme activities.

Data from the present investigation suggest that although oxidative stress occurs following the initial days of highintensity exercise, there is no cumulative effect of successive days of high-intensity exercise on the oxidation of lipids and protein in highly trained cyclists. TAS remains elevated for $24 \mathrm{~h}$ following high-intensity intermittent exercise and may offer protection against subsequent oxidative stress over consecutive days of high-intensity training. Although intense exercise may increase lipid peroxidation, urate oxidation, and plasma TAS, such alterations are not necessarily accompanied by changes in erythrocyte antioxidant activity. As antioxidant defenses were not depleted, highly-trained cyclists appear to have antioxidant defense systems that cope with ROS production associated with 3 consecutive days of high-intensity training. Mechanisms that offer additional protection from oxidative stress during the initial days of consecutive days of high-intensity exercise, such as antioxidant supplementation that may enhance plasma TAS levels and plasma vitamin E levels, require further investigation.

\section{References}

Abuja, P.M. 2001. Atherosclerosis: cell biology and lipoproteins. Curr. Opin. Lipidol. 12: 591-593. doi:10.1097/00041433200110000-00017. PMID:11561180.

Benzie, I.F., Chung, W., and Tomlinson, B. 1999. Simultaneous measurement of allantoin and urate in plasma: analytical evaluation and potential clinical application in oxidant:antioxidant balance studies. Clin. Chem. 45: 901-904. PMID:10352002.

Burton, G.W., Cheeseman, K.H., Doba, T., Ingold, K.U., and Slater, T.F. 1983. Vitamin $\mathrm{E}$ as an antioxidant in vitro and in vivo. Ciba Found. Symp. 101: 4-18. PMID:6557906.

Child, R.B., Wilkinson, D.M., and Fallowfield, J.L. 2000. Effects of a training taper on tissue damage indices, serum antioxidant capacity and half-marathon running performance. Int. J. Sports Med. 21: 325-331. doi:10.1055/s-2000-3778. PMID:10950440.

Criswell, D., Powers, S., Dodd, S., Lawler, J., Edwards, W., Renshler, K., et al. 1993. High intensity training-induced changes in skeletal muscle antioxidant enzyme activity. Med. Sci. Sports Exerc. 25: 1135-1140. PMID:8231758.

Curran-Everett, D. 2000. Multiple comparisons: philosophies and illustrations. Am. J. Physiol. Regul. Integr. Comp. Physiol. 279: R1-R8. PMID:10896857.

Dill, D.B., and Costill, D.L. 1974. Calculation of percentage changes in volumes of blood, plasma, and red cells in dehydration. J. Appl. Physiol. 37: 247-248. PMID:4850854.
Drabkin, D.L. 1965. The molecular weight of haemoglobin, its iron and nitrogen content and optical properties-their relevance in the problem of a rReference standard for haemoglobin measurement. Bibl. Haematol. 21: 33-42. PMID:14336774.

Dufaux, B., Heine, O., Kothe, A., Prinz, U., and Rost, R. 1997. Blood glutathione status following distance running. Int. J. Sports Med. 18: 89-93. doi:10.1055/s-2007-972601. PMID: 9081263.

Duthie, G.G., Robertson, J.D., Maughan, R.J., and Morrice, P.C. 1990. Blood antioxidant status and erythrocyte lipid peroxidation following distance running. Arch. Biochem. Biophys. 282: 78-83. doi:10.1016/0003-9861(90)90089-H. PMID:2221920.

Green, H.J., and Fraser, I.G. 1988. Differential effects of exercise intensity on serum uric acid concentration. Med. Sci. Sports Exerc. 20: 55-59. PMID:3343917.

Grootveld, M., and Halliwell, B. 1987. Measurement of allantoin and uric acid in human body fluids. A potential index of freeradical reactions in vivo? Biochem. J. 243: 803-808. PMID:3663100.

Groussard, C., Machefer, G., Rannou, F., Faure, H., Zouhal, H., Sergent, O., et al. 2003. Physical fitness and plasma non-enzymatic antioxidant status at rest and after a wingate test. Can. J. Appl. Physiol. 28: 79-92. PMID:12671197.

Hellsten, Y., Tullson, P.C., Richter, E.A., and Bangsbo, J. 1996. Oxidation of urate in human skeletal muscle during exercise. Free Radic. Biol. Med. 22: 169-174.

Hutler, M., Woweries, S., Leithauser, R., Boning, D., and Beneke, R. 2001. Exercise-induced changes in blood levels of alpha-tocopherol. Eur. J. Appl. Physiol. 85: 151-156. PMID:11513309.

Jenkins, R.R., and Goldfarb, A. 1993. Introduction: oxidant stress, aging and exercise. Med. Sci. Sports Exerc. 25: 210-212. PMID:8450723.

Ji, L.L. 2002. Exercise-induced modulation of antioxidant defense. Ann. N. Y. Acad. Sci. 959: 82-92. PMID:11976188.

Konig, D., Wagner, K.H., Elmadfa, I., and Berg, A. 2001. Exercise and oxidative stress: significance of antioxidants with reference to inflammatory, muscular, and systemic stress. Exerc. Immunol. Rev. 7: 108-133. PMID:11579745.

Lovlin, R., Cottle, W., Pyke, I., Kavanagh, M., and Belcastro, A. 1987. Are indices of free radical damage related to exercise intensity. Eur. J. Appl. Physiol. Occup. Physiol. 56: 313-316. PMID:3569239.

Madesh, M., and Balasubramanian, K.A. 1998. Microtiter plate assay for superoxide dismutase using MTT reduction by superoxide. Indian J. Biochem. Biophys. 35: 184-188. PMID: 9803669.

Marzatico, F., Pansarasa, O., Bertorelli, L., Somenzini, L., and Della Valle, G. 1997. Blood free radical antioxidant enzymes and lipid peroxides following long-distance and lactacidemic performances in highly trained aerobic and sprint athletes. J. Sports Med. Phys. Fitness, 37: 235-239. PMID:9509820.

Matuszczak, Y., Farid, M., Jones, J., Lansdowne, S., Smith, M.A., Taylor, A.A., et al. 2005. Effects of $N$-acetylcysteine on glutathione oxidation and fatigue during handgrip exercise. Muscle Nerve, 32: 633-638. doi:10.1002/mus.20385. PMID:16025522.

Mena, P., Maynar, M., Gutierrez, J.M., Maynar, J., Timon, J., and Campillo, J.E. 1991. Erythrocyte free radical scavenger enzymes in bicycle professional racers. Adaptation to training. Int. J. Sports Med. 12: 563-566. PMID:1797698.

Merry, P., Grootveld, M., Lunec, J., and Blake, D.R. 1991. Oxidative damage to lipids within the inflamed human joint provides evidence of radical-mediated hypoxic-reperfusion injury. Am. J. Clin. Nutr. 53(Suppl. 1): 362S-369S. PMID:1985412.

Messina, S., Altavilla, D., Aguennouz, M., Seminara, P., Minutoli, 
L., Monici, M.C., et al. 2006. Lipid peroxidation inhibition blunts nuclear factor-kappaB activation, reduces skeletal muscle degeneration, and enhances muscle function in mdx mice. Am. J. Pathol. 168: 918-926. doi:10.2353/ajpath.2006.050673. PMID:16507907.

Mikami, T., Yoshino, Y., and Ito, A. 2000. Does a relationship exist between the urate pool in the body and lipid peroxidation during exercise? Free Radic. Res. 32: 31-39. doi:10.1080/ 10715760000300041. PMID:10625215.

Miller, N.J., Rice-Evans, C., Davies, M.J., Gopinathan, V., and Milner, A. 1993. A novel method for measuring antioxidant capacity and its application to monitoring the antioxidant status in premature neonates. Clin. Sci. (Lond.), 84: 407-412. PMID: 8482045.

Okamura, K., Doi, T., Hamada, K., Sakurai, M., Yoshioka, Y., Mitsuzono, R., et al. 1997. Effect of repeated exercise on urinary 8hydroxy-deoxyguanosine excretion in humans. Free Radic. Res. 26: 507-514. PMID:9212344.

Petibois, C., and Deleris, G. 2005. Erythrocyte adaptation to oxidative stress in endurance training. Arch. Med. Res. 36: 524-531. doi:10.1016/j.arcmed.2005.03.047. PMID:16099333.

Pyne, D.B. 1994. Exercise-induced muscle damage and inflammation: a review. Aust. J. Sci. Med. Sport, 26: 49-58. PMID:8665277.

Senturk, U.K., Gunduz, F., Kuru, O., Aktekin, M.R., Kipmen, D., Yalcin, O., et al. 2001. Exercise-induced oxidative stress affects erythrocytes in sedentary rats but not exercise-trained rats. J. Appl. Physiol. 91: 1999-2004. PMID:11641336.

Shingfield, K.J., and Offer, N.W. 1999. Simultaneous determination of purine metabolites, creatinine and pseudouridine in ruminant urine by reversed-phase high-performance liquid chromatography. J. Chromatogr. B Biomed. Sci. Appl. 723: 8194. doi:10.1016/S0378-4347(98)00549-0. PMID:10080636.

Sim, A.S., Salonikas, C., Naidoo, D., and Wilcken, D.E. 2003. Im- proved method for plasma malondialdehyde measurement by high-performance liquid chromatography using methyl malondialdehyde as an internal standard. J. Chromatogr. B Analyt. Technol. Biomed. Life Sci. 785: 337-344. PMID:12554147.

Subudhi, A.W., Davis, S.L., Kipp, R.W., and Askew, E.W. 2001. Antioxidant status and oxidative stress in elite alpine ski racers. Int. J. Sport Nutr. Exerc. Metab. 11: 32-41. PMID:11334023.

Taibi, G., and Nicotra, C.M. 2002. Development and validation of a fast and sensitive chromatographic assay for all-trans-retinol and tocopherols in human serum and plasma using liquid-liquid extraction. J. Chromatogr. B Analyt. Technol. Biomed. Life Sci. 780: 261-267. PMID:12401351.

Tauler, P., Gimeno, I., Aguilo, A., Guix, M.P., and Pons, A. 1999. Regulation of erythrocyte antioxidant enzyme activities in athletes during competition and short-term recovery. Pflugers Arch. 438: 782-787. doi:10.1007/s004240051107. PMID: 10591066.

Thomas, J.R., Salazar, W., and Landers, D.M. 1991. What is missing in $p<.05$ ? Effect size. Res. Q. Exerc. Sport, 62: 344-348. PMID:1925064.

Vasankari, T.J., Kujala, U.M., Vasankari, T.M., Vuorimaa, T., and Ahotupa, M. 1997. Effects of acute prolonged exercise on-serum and LDL oxidation and antioxidant defences. Free Radic. Biol. Med. 22: 509-513. doi:10.1016/S0891-5849(96)00373-5. PMID:8981043.

Viguie, C.A., Frei, B., Shigenaga, M.K., Ames, B.N., Packer, L., and Brooks, G.A. 1993. Antioxidant status and indexes of oxidative stress during consecutive days of exercise. J. Appl. Physiol. 75: 566-572. PMID:7693646.

Wheeler, C.R., Salzman, J.A., Elsayed, N.M., Omaye, S.T., and Korte, D.W., Jr. 1990. Automated assays for superoxide dismutase, catalase, glutathione peroxidase, and glutathione reductase activity. Anal. Biochem. 184: 193-199. doi:10.1016/00032697(90)90668-Y. PMID:2327564. 
Copyright of Applied Physiology. Nutrition \& Metabolism is the property of NRC Research Press and its content may not be copied or emailed to multiple sites or posted to a listserv without the copyright holder's express written permission. However, users may print, download, or email articles for individual use. 